\title{
Geometria do Táxi: Resolvendo Problemas de Rotina
} (Taxicab: Solving Problems Routine)

\section{JOSÉ CARLOS PINTO LEIVAS}

\section{Centro Universitário Franciscano (leivasjc@unifra.br)}

Resumo. Neste artigo, apresentamos resultados de uma pesquisa qualitativa, realizada no primeiro semestre do ano de 2014, numa disciplina de Geometria, que teve como objetivo responder ao questionamento: como estudantes de um mestrado profissionalizante em ensino de Matemática utilizam recursos didáticos e tecnológicos para resolver problemas envolvendo Geometria do Táxi? A partir de atividade inicial de localização de pontos e construção de conhecimentos sobre a métrica do táxi ou dos catetos, foram propostas situações-problema reais distintas a cada aluno, para que resolvessem durante certo período e as reunissem em um seminário com a turma toda. Durante a realização desse, foram retomadas algumas soluções e chegamos à formalização dos conceitos de ponto médio e mediatriz na Geometria do Táxi e respectiva comparação com os mesmos conceitos na Geometria Euclidiana. As representações dos estudantes, em papel milimetrado e quadriculado, e o auxílio do software GeoGebra, na resolução da sequência de situações-problema, permitiram concluir que tais conceitos foram adquiridos e aplicados de forma satisfatória.

Abstract. This article presents results of a qualitative research conducted in the first semester of 2014 in a Geometry course, which aimed to answer the question: how students of a professional Masters in Mathematics Teaching, using didactic and technological resources to solve problems involving Taxicab Geometry? From an initial activity of location of points and building knowledge about the taxi'metric, it was proposed situationsproblem real and distinct for every student to solve for some time and they meet at a workshop with the whole class. During the realization of this we resumed some solutions and we come to formalize the concepts of midpoint and mediatrix in Taxicab Geometry and its comparison with the same concepts in Euclidean Geometry. The representations of students, on squared paper and the help of GeoGebra in the resolution of the sequence of situations-problem activities, showed that such concepts were purchased and applied to fully satisfactorily.

Palavras-chave: geometria do táxi, situações-problema, ponto médio, mediatriz

Keyword: Taxicab Geyometry, solving problems, midpoint, mediatrix

\section{Introdução}

A riqueza de conhecimentos que a Geometria tem oferecido, no decorrer dos tempos, é muito grande, parece não parar de crescer, cabendo novos desafios aos estudiosos dessa área, a cada época, na tentativa de resolver problemas. Conforme a história, aproximadamente há 2.400 anos, o grego Aristóteles estava em pé, na orla marítima, observando navios desaparecerem na distância, quando se questionou sobre como poderiam ir diminuindo na linha do horizonte até sumirem, se a terra, até então, era considerada plana. Dessa forma, surgiu a hipótese de ela ser curva. (MLODINOW, 2010).

Com a genialidade de Descartes, o qual associou coordenadas aos objetos geométricos, esses foram amplamente contextualizados com a Física, por exemplo, com a ideia dos espaços curvos e, com isso, foi questionado como ficaria a soma dos ângulos internos de um triângulo nesses espaços. Continuaria a ser igual a $180^{\circ}$ ou somaria mais ou menos do que esse valor? 
A Geometria assumiu, assim, novos horizontes, além do euclidiano grego, que tratou da representação dos objetos do mundo real ou perceptível (ponto, reta, plano e espaço) aos quais está atrelada a questão de medida, ou seja, a métrica euclidiana. Foi nos séculos XIX e XX que ela passou ao mundo imaginário, o que permitiu a explicação de fenômenos não newtonianos para a Nova Física, a partir da qual os fenômenos não são mais locais. Criaram-se as geometrias não euclidianas Elíptica e Hiperbólica.

De Maio e Chiummo (2008, p.4) fazem o seguinte questionamento: "Se nosso Universo não é euclidiano e a Física newtoniana não representa a realidade, por que, no cotidiano e nas escolas, continuamos a utilizar a Geometria euclidiana e a Física newtoniana?". Afirmam esses autores que a resposta está nos mundos físico e perceptível e, por causa do último, é que continuamos a ensinar, exclusivamente, a Geometria euclidiana.

A esse respeito, os Parâmetros Curriculares Nacionais-PCN (BRASIL, 1998) apontam que a Matemática "caracteriza-se como uma forma de compreender e atuar no mundo e o conhecimento gerado nessa área do saber é como um fruto da construção humana na sua interação constante com o contexto natural, social e cultural.” (p. 24). De acordo com o documento, na sequência, essa visão da disciplina opõe-se ao que é comumente encontrado, na escola e na sociedade, as quais consideram "a Matemática como um corpo de conhecimento imutável e verdadeiro.” (p. 24)

Os PCN, documento orientador para o ensino de Matemática, reiteram, portanto, o que indica Granger (1974, p. 16): “o conhecimento científico, tido como um processo de conceitualização, consiste em reduzir o que é experimentado, na percepção, como individual, isto é, como momento concreto vivido em tal situação". Portanto, proporcionar aos estudantes situações-problema para resolver e que possam vislumbrála em seu cotidiano, possibilitará a aquisição de novos paradigmas para a Geometria, como os que expomos no presente artigo e que o justificam, a saber, resolução de problemas envolvendo uma métrica não euclidiana, a denominada "dos catetos" ou "do táxi” ou "urbana", a qual gera uma geometria não euclidiana, chamada Geometria do Táxi.

A resolução de problemas é recomendada nos PCN como sendo o eixo organizador do processo de ensino e aprendizagem de Matemática e se resume em alguns princípios, dos quais destacamos: 
o problema certamente não é um exercício em que o aluno aplica, de forma quase mecânica, uma fórmula ou um processo operatório. Só há problema se o aluno for levado a interpretar o enunciado da questão que lhe é apresentada. A resolução de problemas não é uma atividade para ser desenvolvida em paralelo ou como aplicação da aprendizagem, mas uma orientação para a aprendizagem, pois proporciona o contexto em que se pode aprender conceitos, procedimentos e atitudes matemáticas. (BRASIL, 1998, p. 41)

No que diz respeito ao bloco Espaço e Forma, o documento explicita que o estudo da Geometria é um campo fértil para trabalhar com situações-problema, sendo um tema de interesse natural por parte dos alunos. Em particular, para o terceiro ciclo do Ensino Fundamental, indica a "interpretação, a partir de situações-problema (leitura de plantas, croquis, mapas), da posição de pontos e de seus deslocamentos no plano, pelo estudo das representações em um sistema de coordenadas cartesianas" (Idem, p. 72). Dessa forma, a Geometria do Táxi é aquela que entendemos como mais próxima da realidade cotidiana, pois é utilizando um sistema retangular ideal que podemos realizar deslocamentos em uma cidade ideal imaginária, organizada em ruas, de modo similar ao sistema cartesiano ortogonal. Nessa geometria, denominada por Fossa (2001) como Geometria Urbana, a métrica euclidiana não se coaduna. Portanto, interpretar e representar localizações e deslocamentos no plano é uma das necessidades para o desenvolvimento do pensamento geométrico.

Além do exposto, comungamos com Duval (2011) quando, ao tratar da revolução semiótica para a representação e o conhecimento, afirma: "A análise do conhecimento não deve considerar apenas a natureza dos objetos estudados, mas, igualmente, a forma como os objetos nos são apresentados ou como podemos ter acesso por nós mesmos" (p.15).

Assim, é interessante considerar que a interatividade e a aprendizagem colaborativa ocorrem, por meio da participação dos alunos, nas diversas formas de utilização da Geometria do Táxi.

A partir desses pressupostos, justifica-se o seguinte problema de pesquisa: como estudantes de um mestrado profissionalizante em ensino de Matemática, em uma disciplina de Geometria, utilizam recursos didáticos e tecnológicos para resolver problemas envolvendo a Geometria do Táxi?

\section{Geometria do Táxi}

A Geometria do Táxi [Taxicab Geometry] é pouco conhecida no Brasil, muito embora a métrica dos catetos seja familiar para estudantes de Topologia. Ela recebeu 
esse nome e foi divulgada por Hermann Minkowski (1864-1909). Segundo Krause (1986, p.vi, trad. nossa), "aparentemente, ninguém ainda configurou uma geometria completa com base na métrica do táxi”.

Denominamos métrica do táxi ou métrica dos catetos à função d: $\mathbb{R}^{2} \rightarrow \mathbb{R}^{2}$, que associa, a cada par ordenado $\mathrm{A}=\left(\mathrm{x}_{\mathrm{A}}, \mathrm{y}_{\mathrm{A}}\right), \mathrm{B}=\left(\mathrm{x}_{\mathrm{B}}, \mathrm{y}_{\mathrm{B}}\right)$, o número real não negativo definido por

$$
d(A, B)=\left|x_{A}-x_{B}\right|+\left|y_{A}-y_{B}\right|
$$

O número real 'd' é denominado de distância de A até B.

A interpretação geométrica dessa métrica é dada na figura 1. Enquanto na Geometria Euclidiana a distância entre os pontos A e B é dada pela medida do segmento tracejado, na Geometria do Táxi, ela ocorre pela reunião das medidas dos segmentos AC e CB. Em virtude disso, por vezes, é denominada métrica dos catetos, em vez de métrica táxi.

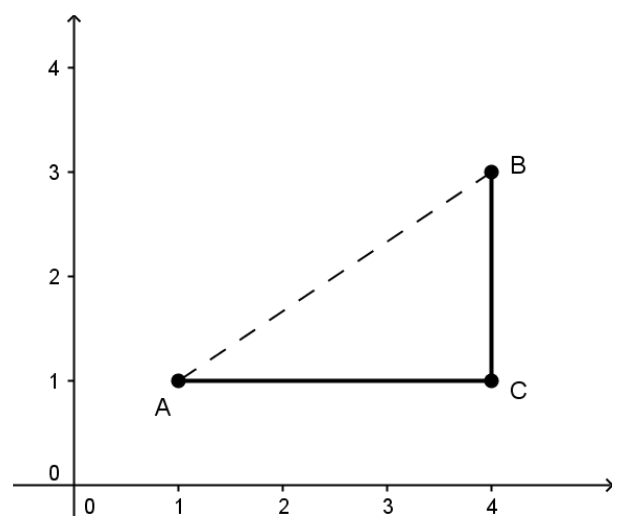

Figura 1-Métrica do táxi ou dos catetos.

É interessante observar que,

para apreciar plenamente a geometria euclidiana, é preciso ter algum contato com uma não-euclidiana. Idealmente, uma geometria não-euclidiana escolhida deve: (1) estar muito próxima da Geometria euclidiana em sua estrutura axiomática; (2) ter aplicações importantes; (3) ser entendida por qualquer pessoa que tenha passado por um curso de geometria euclidiana. A condição (1) exclui as diversas geometrias finitas, bem como a (elíptica) geometria da esfera. (Ibidem, p.v, trad. nossa) 
As geometrias finitas, por exemplo, como o próprio nome indica, são constituídas de finitos pontos, ao contrário da euclidiana; a elíptica não possui retas paralelas e a hiperbólica apresenta mais do que uma reta passando por um determinado ponto. A Geometria Hiperbólica, assim como a Geometria Elíptica, satisfaz a primeira e a segunda condição, entretanto, difere da última, por ser uma construção matemática relativamente sofisticada, havendo vários modelos axiomáticos como, por exemplo, o de Poincaré e o de Klein.

Por sua vez, a Geometria do Táxi, uma das não-euclidianas, satisfaz às três condições de maneira relativamente simples e, até certo ponto, de fácil visualização geométrica, uma vez que pode ser empregada na urbanização de uma cidade ideal, na qual as ruas são organizadas em quarteirões.

Visualização é um tema de investigação atual, já existindo literatura abundante a respeito. Neste artigo ela é compreendida no sentido indicado por Zimmermann e Cunningham (1991, p. 3), como: “o processo de formação de imagens (mentalmente, ou com papel e lápis, ou com o auxílio de tecnologia) e utilização dessas imagens para descobrir e compreender matemática”. Wagner e Flores (2015) discutem mobilizações de discussões sobre modos de ver a Matemática, na tentativa de "desnaturalizar práticas instituídas, problematizando os modos de ver existentes e criando outras condições para pensar sobre a visualização matemática e os efeitos dela no ensino”. (p. 110)

Trabalhar com essa geometria, no ensino médio, pode ser uma boa forma de incentivar os estudantes à aprendizagem da função modular, essencial para os que irão frequentar cursos superiores na área de ciências exatas. Também pode despertar a curiosidade para representações dos lugares geométricos correspondentes aos da Geometria Euclidiana, como parábolas, elipses e hipérboles (LEIVAS, 2014).

Para Laatsch (1982), em vez de ser usada a definição de "ponto-reta", alguns resultados interessantes podem ser mostrados com forte analogia entre as figuras na Geometria do Táxi, e as cônicas euclidianas. Em primeiro lugar, as táxi-figuras, obtidas usando o foco e a diretriz da elipse, parábola e hipérbole podem ser obtidas projetando seções planas de uma pirâmide quadrada sobre um plano perpendicular ao eixo da pirâmide. (A pirâmide quadrada é o objeto natural para a seção, visto que é a análoga ao cone circular reto).

Uma analogia entre a táxi-circunferência e a circunferência euclidiana é construída por Leivas (2003), que denomina a região limitada por ela de bola quadrada, o que desperta nos estudantes um interesse grande, pelos cálculos analíticos e a 
respectiva representação geométrica ou visualização. Em termos de ensino de equações de retas, a atividade com coeficientes angulares e lineares, no plano, pode ser desenvolvida no Ensino Médio, estabelecendo importante conexão entre a visualização geométrica de retas e expressões analíticas correspondentes.

Sowell (1989), no estudo de movimentos rígidos do plano, usa grades isométricas, para trabalhar com a métrica da Geometria do Táxi. O autor afirma que,

$$
\begin{aligned}
& \text { na iso-táxi geometria, dois segmentos são definidos como sendo congruentes, } \\
& \text { se e somente se eles têm o mesmo iso-táxi comprimento. As transformações } \\
& \text { do plano que preservam as iso-táxi distâncias são reflexões sobre qualquer } \\
& \text { linha, de tal forma que o ângulo que ela faz com a horizontal é um múltiplo } \\
& \text { de } 30^{\circ} \text {. Em todas as translações e rotações em torno de qualquer ponto, o } \\
& \text { ângulo de rotação é um múltiplo de } 60^{\circ} \text {. (p. } 239 \text {, tradução nossa) }
\end{aligned}
$$

Neste artigo, tratamos conceitos dessa geometria correlatos a ponto médio e mediatriz de segmentos da Geometria Euclidiana, por exemplo, como partes do arcabouço geométrico organizado lógica e rigorosamente a partir de uma estrutura. Assim, a partir de procedimentos de ensino adequados, é possível desenvolver uma geometria de forma conceitual, perfeitamente estruturada e compatível, a exemplo do que fez Euclides.

Fossa (2001) considera que a Geometria Analítica impõe a métrica usual, de maneira puramente formal, o que dificulta uma compreensão mais profunda das funções e seus gráficos. Diz o autor que, "para ajudar o aluno a construir as estruturas matemáticas necessárias para o referido estudo, propomos uma volta a situaçõesproblema que retratam mais fielmente a experiência vivida pelo aluno do que geralmente encontradas na abordagem tradicional.” (p. 90).

$\mathrm{O}$ autor indica que, para garantir a existência de uma distância entre dois pontos, na cidade imaginária ideal, é necessário que consideremos um número infinito de ruas, ou seja, para cada número real $\mathrm{k}, \mathrm{x}=\mathrm{k}$ e $\mathrm{y}=\mathrm{k}$ são as ruas que formam uma malha retangular. Se for considerado k um número real, a fim de obter um número infinito de ruas, a situação não seria real, pela continuidade do conjunto dos números reais, pois não haveria espaços entre uma e outra para deslocamentos e construções, como ocorre concretamente.

Souza (2015) realizou uma pesquisa com estudantes do Ensino Médio, na qual utilizou o GeoGebra, para estudar o deslocamento deles desde suas residências até a escola. Utilizou, também, situações hipotéticas de corridas e deslocamentos em maratonas. Concluiu que o software foi um aliado relevante para a construção de conceitos nessa geometria. 
Para Kaleff e Nascimento (2004, p. 13):

[...] a Geometria do Táxi pode ser apresentada, com a intenção de se integrar a Matemática ao cotidiano do aluno, pois essa se apresenta em todos os lugares, não podendo, portanto, deixar de ser encontrada no espaço das "ruas". Dessa forma, confrontado com esta nova Geometria, o aluno pode ser levado a perceber que existem outras Geometrias, além da Euclidiana, possibilitando que tenha despertada a sua curiosidade para novos ambientes matemáticos.

Ekici, Kocayusufo e Akça (1998) informam que ela difere da Geometria Euclidiana em apenas um axioma, dentre aqueles que correspondem à congruência de triângulos (lado-ângulo-lado) e que têm uma ampla gama de aplicações no mundo urbano, sendo fácil entendê-la.

\title{
Resolução de Problemas
}

A metodologia de resolução de problemas é uma das mais empregadas na Educação Matemática, talvez por ser preconizada pelos documentos oficiais brasileiros. O Referencial Curricular Nacional para a Educação Infantil-RCNEI (BRASIL, 2006), no que diz respeito às orientações didáticas para esse segmento do ensino, indica a resolução de problemas como forma de aprendizagem e, quanto à Geometria, salienta:

\begin{abstract}
o pensamento geométrico compreende as relações e representações espaciais que as crianças desenvolvem, desde muito pequenas, inicialmente, pela exploração sensorial dos objetos, das ações e deslocamentos que realizam no meio ambiente, da resolução de problemas. Cada criança constrói um modo particular de conceber o espaço, por meio das suas percepções, do contato com a realidade e das soluções que encontra para os problemas. (p. 109)
\end{abstract}

Por sua vez, os PCN indicam "a Resolução de Problemas como ponto de partida da atividade Matemática e discutem caminhos para 'fazer Matemática' na sala de aula, destacando a História da Matemática e as Tecnologias da Comunicação" (BRASIL, 1998, p. 16). Quanto ao Ensino Médio, afirmam que essa metodologia envolve o tratamento de situações complexas e diversificadas, a fim de que o estudante tenha oportunidade de "pensar por si mesmo, construir estratégias de resolução e argumentações, relacionar diferentes conhecimentos e, enfim, perseverar na busca da solução. E, para isso, os desafios devem ser reais e fazer sentido." (BRASIL, 1999, p.110). Indicam, ainda, que,

para alcançar os objetivos estabelecidos de promover as competências gerais e o conhecimento de Matemática, a proposta dos PCNEM privilegia o tratamento de situações-problema, preferencialmente tomadas em contexto real. A resolução de problemas é a perspectiva metodológica escolhida nessa proposta e deve ser entendida como a postura de investigação frente a qualquer situação ou fato que possa ser questionado. (p.126) 
Polya (2006), um dos precursores da metodologia da resolução de problemas, aponta quatro fases: compreensão do problema; plano de resolução; execução do plano; retrospecto da resolução completa. Na primeira, o aluno tem de entender claramente o que é solicitado e resolver; na segunda, deve buscar ligação entre a incógnita e os dados fornecidos, a fim de elaborar ideia de como proceder à resolução; na terceira, precisa executar o plano delineado na etapa precedente para, finalmente, na última, revisitar sua resolução, discutindo-a.

Um problema para Hiebert et al. (1997, apud VAN DE WALLE, 2009) é uma "tarefa ou atividade na qual os estudantes não tenham nenhum método ou regra já receitados ou memorizados e nem haja uma percepção por parte dos estudantes de que haja um método ‘correto’ específico de solução”. (p. 57).

A metodologia ensino-aprendizagem-avaliação de Matemática, através da resolução de problemas,

tem o objetivo de expressar uma concepção de que ensino e aprendizagem devem ocorrer simultaneamente durante a construção do conhecimento, tendo o professor como guia e os alunos como co-construtores desse conhecimento. Além disso, essa metodologia integra uma concepção mais atual sobre avaliação." (ONUCHIC; ALLEVATO, 2009, p. 97).

Para as autoras, as etapas da metodologia são: preparação do problema; leitura individual; leitura em conjunto; resolução do problema; observação e iniciativa; exploração, na lousa, dos diferentes resultados encontrados; estímulo para que os grupos defendam seus pontos de vista; promoção de consenso; formalização das devidas definições.

Ao tratar sobre as perspectivas matemáticas de problemas os quais são problemáticos, Schoenfeld (1992) afirma que é difícil haver unanimidade entre matemáticos sobre concepções de resolução de problemas e indica que

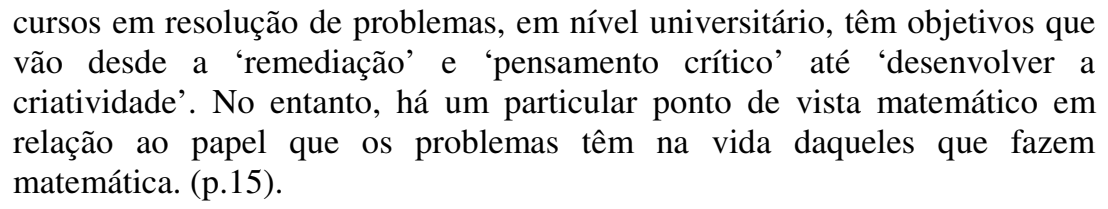
cursos em resolução de problemas, em nível universitário, têm objetivos que vão desde a 'remediação' e 'pensamento crítico' até 'desenvolver a criatividade'. No entanto, há um particular ponto de vista matemático em relação ao papel que os problemas têm na vida daqueles que fazem matemática. (p.15).

Apesar das diferentes correntes nessa metodologia, há coincidência sobre a sua relevância para o ensino. Assim, propomos desenvolver, durante algumas aulas de uma disciplina de Geometria, num Mestrado Profissional em Ensino de Matemática, atividades relativas à Geometria do Táxi, utilizando características dessa metodologia, não necessariamente seguindo rigorosamente cada passo daqueles indicados pelos autores citados neste artigo. 


\section{A pesquisa}

A pesquisa foi realizada, no primeiro semestre letivo do ano de 2015, no desenrolar da disciplina de Geometria, com treze alunos, sob a responsabilidade do autor deste artigo. Caracteriza-se como qualitativa ou naturalista, segundo Moreira (2011), por não envolver a manipulação de variáveis e nem o tratamento experimental. Para D’Ambrosio (2004), a “pesquisa qualitativa é outra coisa. No meu entender, é o caminho para escapar da mesmice. Lida e dá atenção às pessoas e às suas ideias, procura fazer sentido de discursos e narrativas que estariam silenciosas. E a análise dos resultados permitirá propor os novos passos" (p. 21). Nessa disciplina, buscamos desenvolver com os estudantes uma postura para o ensino de Geometria que não seja a pura reprodução de conceitos e demonstrações.

Entendemos que a pesquisa em apreço contribui para o desenvolvimento da área de Geometria junto ao Programa de Pós-Graduação no qual a disciplina está inserida, o que corrobora o preconizado por Alves-Mazzotti e Gewandsznajder (2002), segundo os quais deve trazer benefício para a comunidade e para a instituição e, em se tratando de formação continuada de professores, terá uma expansão no âmbito regional, estadual e nacional.

Considerando que, nas pesquisas qualitativas, os dados são multimetodológicos, isto é, usam grande variedade de procedimentos e instrumentos, segundo AlvesMazzotti e Gewandsznajder (2002), utilizamos produção escrita dos alunos, antecipada ao desenvolvimento do conteúdo novo pelo professor (Geometria do Táxi); atividades preliminares sobre o conteúdo; proposição de situações-problema envolvendo o novo conteúdo (uma vez que nenhum aluno tinha conhecimento prévio do assunto); resolução de atividade individual de situação-problema distribuída a cada aluno; encaminhamento dessas, por escrito, ao professor pesquisador; apresentação e discussão, em grande grupo, das soluções encontradas; retomada pelos participantes que não obtiveram solução correta.

Como um dos procedimentos da coleta de dados é a observação, durante as apresentações e debates do grande grupo, tivemos oportunidade de anotar para, posteriormente, analisar.

As seguintes vantagens costumam ser atribuídas à observação: a) independe do nível de conhecimento ou da capacidade verbal dos sujeitos; b) permite 'checar', na prática, a sinceridade de certas respostas que, às vezes, são dadas só para 'causar boa impressão'; c) permite identificar comportamentos nãointencionais ou inconscientes e explorar tópicos que os informantes não se 
sentem à vontade para discutir; d) permite o registro do comportamento em seu contexto temporal-espacial. (Ibidem, p. 164)

Duas semanas antes da aula na qual iniciaríamos o conteúdo Geometria do Táxi, solicitamos que os alunos encaminhassem um texto de, no máximo, uma página, dentro de um template previamente fornecido, a respeito do tema. Essa prática é utilizada na disciplina, a fim de que a aula possa fluir a partir de um conhecimento prévio dos estudantes a respeito de cada assunto novo. O encaminhamento é feito, por meio da postagem, em um grupo criado especificamente para a disciplina e 24 horas antes de acontecer a aula para a respectiva análise e correção. A partir desse contato prévio com o tema, desenvolvemos atividades diversas envolvendo os conceitos iniciais sobre Geometria do Táxi e representações geométricas em malhas quadriculadas. Utilizamos papel milimetrado, quadriculado e o software GeoGebra.

Retomando o problema já citado: como estudantes de um mestrado profissionalizante em ensino de Matemática, em uma disciplina de Geometria, utilizam recursos didáticos e tecnológicos para resolver problemas envolvendo Geometria do Táxi?, definimos os seguintes objetivos da pesquisa:

- relacionar observações do mundo real com diversos tipos de se registrar graficamente representações, tais como: esquemas, tabelas, figuras e mapas;

- relacionar as representações com princípios e conceitos matemáticos;

- identificar os conhecimentos matemáticos como meios para compreender e transformar o mundo à sua volta;

- resolver situações-problema adotando estratégias, desenvolvendo formas de raciocínio e procedimentos matemáticos ligados à intuição, indução, analogia e estimativas de dados;

- interagir com os colegas de modo cooperativo, aprendendo a trabalhar em conjunto na busca de soluções.

Todas as situações-problema foram realizadas pelos alunos da disciplina de Geometria do mestrado, como citado antes. A que segue foi proposta e resolvida em aula, consideramos que ela é necessária para a sequência proposta aos alunos.

Para a realização da situação-problema 1, utilizamos o GeoGebra e os estudantes gravaram suas representações e as encaminharam diretamente por meio digital.

O objetivo da situação-problema foi representar pontos na Geometria do Táxi que se encontravam a uma mesma distância de um ponto fixo e buscar analogia com o 
lugar geométrico circunferência na Geometria Euclidiana. Para sua resolução, os alunos utilizaram os notebooks individuais, mas poderiam conversar entre si sobre o problema.

\section{Situação-Problema 1}

Dado o ponto $A=(1,1)$ localize os pontos $P_{i}(i=1,2,3, \ldots, 16)$, na Geometria do Táxi, cuja distância ao ponto A seja igual a 4 unidades, sendo:

$\mathrm{P}_{1}=(-3,1) ; \quad \mathrm{P}_{2}=(-2,2) ; \quad \mathrm{P}_{3}=(-1,3) ; \quad \mathrm{P}_{4}=(0,4) ; \quad \mathrm{P}_{5}=(1,5) ; \quad \mathrm{P}_{6}=(2,4) ; \quad \mathrm{P}_{7}=(3,3,) ; \quad \mathrm{P}_{8}=(4,2) ;$ $\mathrm{P}_{9}=(5,1) ; \mathrm{P}_{10}=(4,0) ; \mathrm{P}_{11}=(3,-1) ; \mathrm{P}_{12}=(2,-2) ; \mathrm{P}_{13}=(1,-3) ; \mathrm{P}_{14}=(0,-2) ; \mathrm{P}_{15}=(-1,-1) ; \mathrm{P}_{16}=(-$ $2,0)$.

Não houve dificuldade, por parte dos estudantes, de representarem os pontos Pi. A figura 2 ilustra uma solução realizada no GeoGebra.

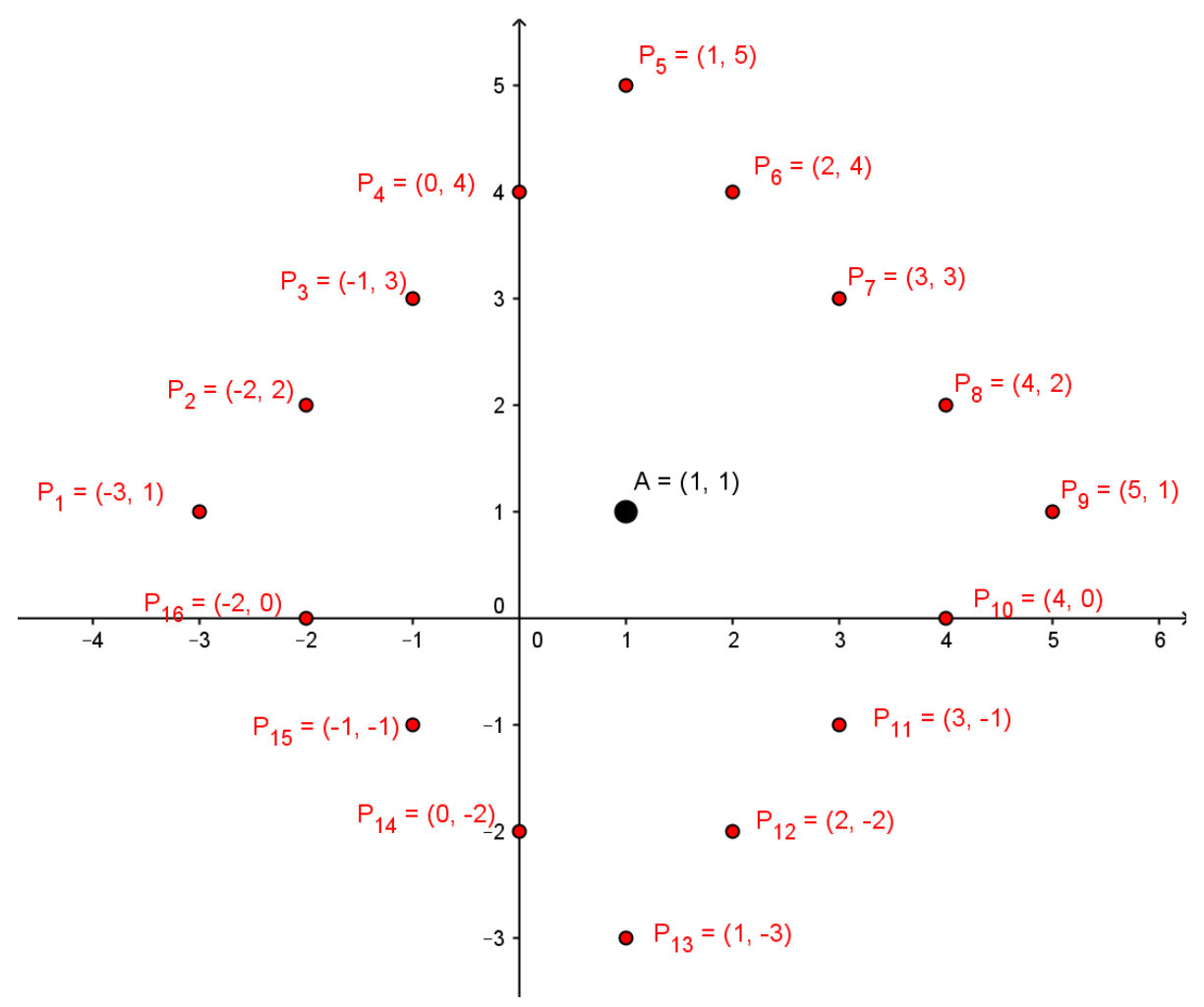

Figura 2 - Pontos na métrica do Táxi.

Fonte: construção no GeoGebra, feita pelo autor.

a) Como você enunciaria essa situação algebricamente?

Os alunos tiveram algumas dificuldades para escrever corretamente, o que comprova problemas existentes de interpretação e escrita de docentes oriundos de uma Licenciatura em Matemática, segundo nossa experiência de mais de uma década como coordenador de uma dessas e como professor do ensino superior por mais de trinta anos. Assim, os pontos $\mathrm{P}_{\mathrm{i}}$ constituem o conjunto:

$$
\left.\left\{P_{\mathrm{i}} \mid d_{T}\left(P_{i}, A\right)=4\right\} \text { em que } i=1,2,3, \ldots ., 16\right\} \text {. }
$$


b) Identifique, se possível, o lugar geométrico, na Geometria Euclidiana, dado por essa lei algébrica.

Alguns confundiram circunferência com a região limitada pela mesma e outros não conseguiram elaborar a definição. Confundiram-se quanto ao conceito de equidistância. Julgamos importante, em se tratando de definir lugares geométricos por leis matemáticas, a distinção entre linhas e regiões, porquanto uma circunferência é uma curva (igualdade na lei de definição) e círculo é uma região (desigualdade na lei de definição). Ao primeiro, deve estar associada a grandeza comprimento, enquanto que, ao segundo, a grandeza área, objetos geométricos discutidos durante a disciplina. Assim, na Geometria Euclidiana, o lugar geométrico dos pontos equidistantes de um ponto dado é denominado de circunferência.

c) A partir da representação feita, obtenha o lugar geométrico dos infinitos pontos que seguem a sequência lógica dada pelos pontos representados na Geometria do Táxi.

Como foi realizada discussão em torno das representações e das definições, todos os alunos assimilaram tais conceitos e obtiveram uma representação como a da figura 3 .

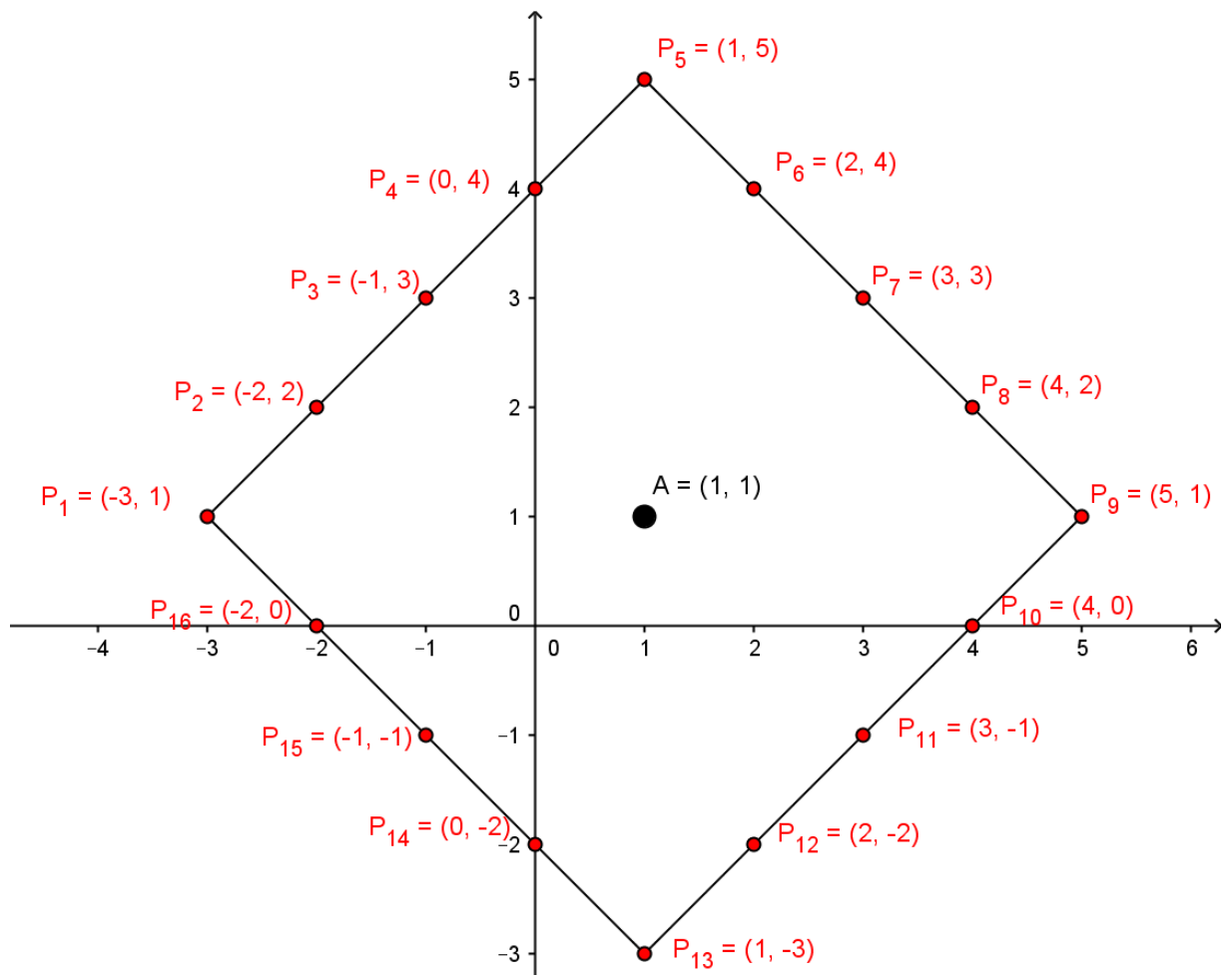

Figura 3 - Circunferência na métrica do táxi.

Fonte: construção no GeoGebra, feita pelo autor. 
Naturalmente, houve dificuldade na aceitação de que a representação dada pela figura 3 é de uma circunferência de centro em A e raio 4, muito embora isso fosse inegável a partir da definição do lugar geométrico, formalizada. Isso fortalece a indicação de que há dificuldades em sair do espaço perceptivo ou real, segundo Euclides, para a aceitação desses novos espaços, muito embora a Geometria do Táxi seja muito concreta.

d) Em uma terceira representação, reúna aquelas do mesmo lugar geométrico nas duas geometrias.

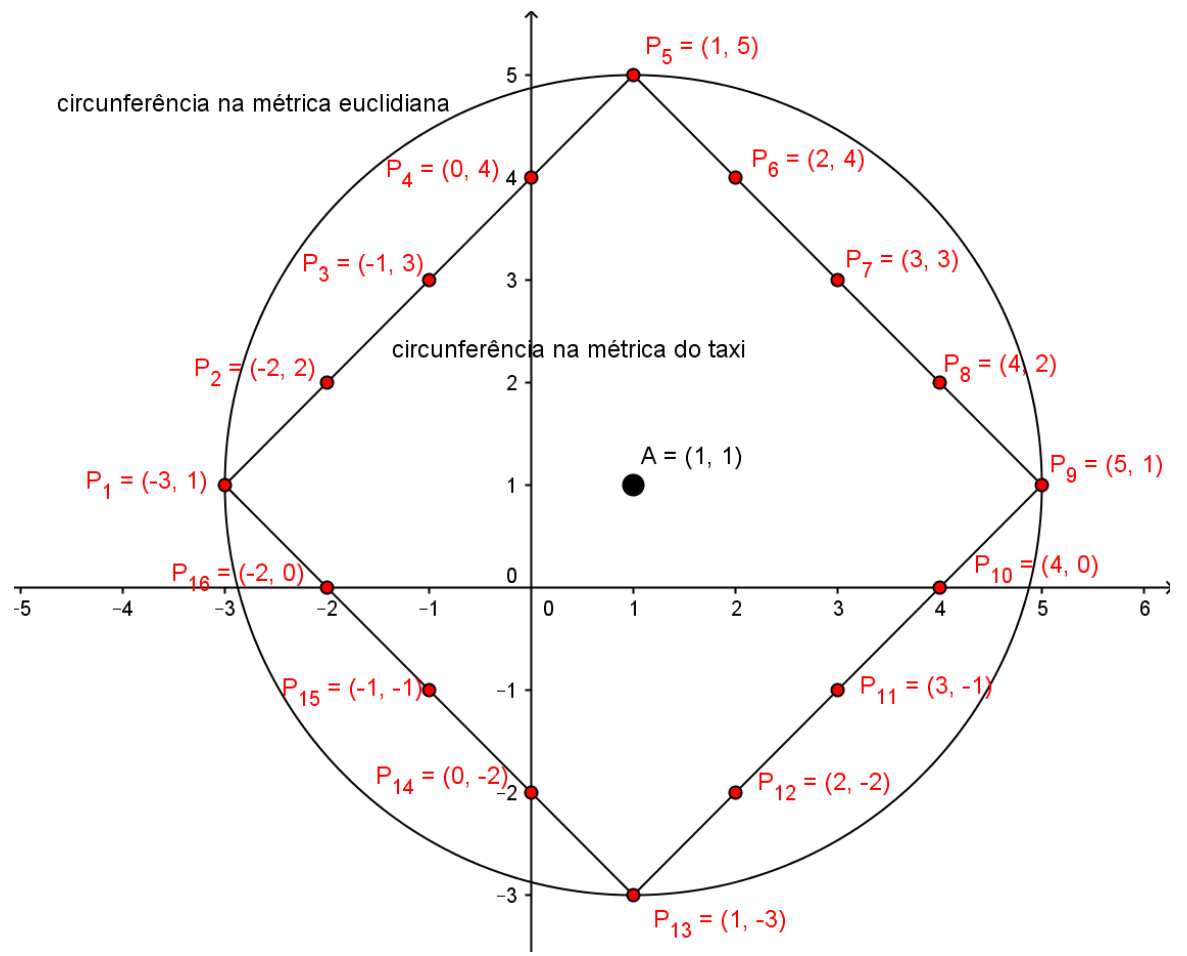

Figura 4 - Circunferência nas duas métricas.

Fonte: construção no GeoGebra, feita pelo autor.

Entendemos que essa primeira situação-problema atendeu a um dos objetivos da metodologia, indicado por Onuchic e Allevatto (2009), quanto ao ensino e à aprendizagem ocorrerem simultaneamente durante a construção do conhecimento em que o professor é o guia do processo.

Após essa etapa e, considerando que os alunos adquiriram conhecimentos básicos sobre o conteúdo, foi distribuída uma folha com uma situação-problema envolvendo a Geometria do Táxi para cada aluno resolver. Tal situação se encaixava num problema hipotético de uma cidade imaginária ideal em que as ruas formavam quadras bem organizadas, como se constituíssem um sistema ortogonal plano. Destinamos um prazo de duas semanas para a resolução do problema e a organização de um seminário no qual seriam apresentadas as respectivas soluções de cada situação- 
problema. Consideramos que, durante as aulas, não foram resolvidas situações similares. Para facilitar a descrição e análise, os participantes foram nomeados por $A_{1}$, $\mathrm{A} 2, \ldots ., \mathrm{A}_{13}$, para preservar suas identidades.

Escolhemos para este artigo, a sequência de problemas que conduziram aos conceitos de ponto médio e mediatriz, uma vez que não caberiam, em um só artigo, todos eles, pela limitação de espaço.

Para o que segue, estipulamos o seguinte objetivo: levar o aluno a perceber que é possível obter diferentes caminhos para realizar um deslocamento entre dois pontos e averiguar o menor percurso possível, utilizando a Geometria do Táxi.

A tarefa foi proposta para ser resolvida em casa, sem auxílio do professor e os recursos a serem utilizados poderiam ser o GeoGebra, papel quadriculado ou milimetrado. Cada aluno recebeu uma tarefa com dados diferentes, embora houvesse alguma similaridade.

\section{Situação-problema $2^{1}$}

Alice e Bruno estão olhando apartamentos numa cidade ideal. Alice trabalha no parque de diversões, localizado em $\mathrm{A}=(-3,-1)$, e Bruno, na padaria localizada em $\mathrm{B}=$ $(3,3)$. Sendo eles ecologicamente conscientes, caminham até onde trabalham. Decidiram comprar seu apartamento e que ele deveria ser localizado próximo, de modo que a distância que Alice teria de caminhar para seu trabalho, mais a distância que Bruno teria de caminhar para o seu, fosse a menor possível. Localize, no mapa, onde eles devem procurar apartamento. Descreva o procedimento matemático utilizado para obter sua resposta.

\section{Solução apresentada pelo aluno $\mathrm{A}_{1}$.}

Inicialmente, o aluno calculou o número mínimo de quadras que separam o trabalho de Alice do de Bruno, obtendo o valor de 10.

Todas as possibilidades em que a soma seja 10 devem ser levadas em consideração $(5+5,6+4,7+3,8+2,9+1)$. Logo, podemos considerar um retângulo de $7 \times 5$ e todos os seus pontos internos (Figura 5), que podem ser $7 \times 5=35$; porém, devemos desconsiderar o ponto onde fica a padaria e o parque: $35-2=33$ são as possibilidades de moradia para Alice e Bruno, capazes de satisfazer o problema inicial. $\left(\mathrm{A}_{1}\right)$

\footnotetext{
${ }^{11}$ As atividades foram adaptadas de Krause (1986).
} 


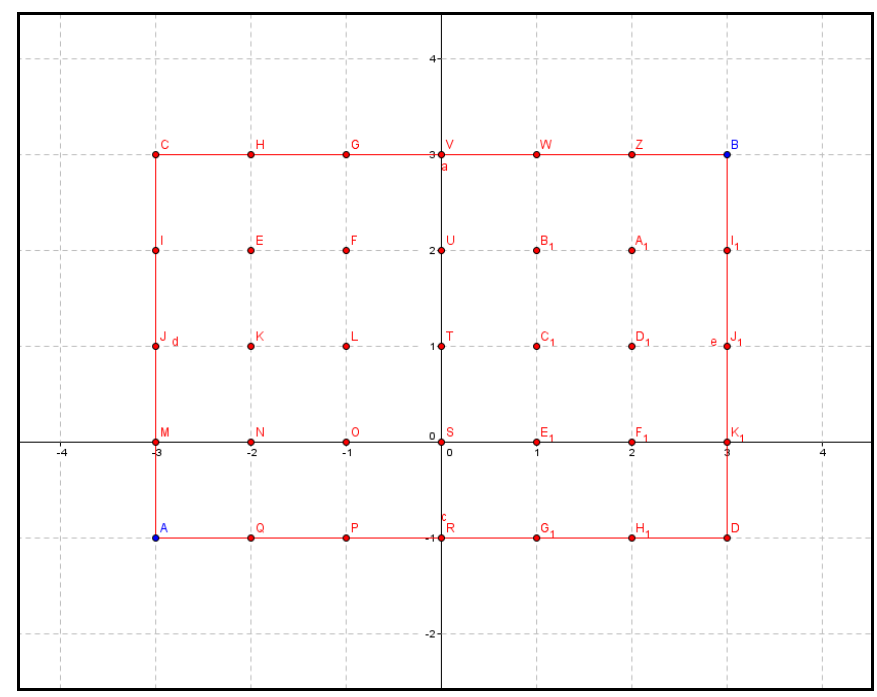

Figura 5 - Possibilidade de moradia para Alice e Bruno. Fonte: $\mathrm{A}_{1}$

O aluno, no entanto, não interpreta adequadamente o problema e acrescenta uma condição que não faz parte do mesmo, a saber, "para que fique justo, se deve sugerir a Alice e Bruno que ambos caminhem a mesma distância entre sua casa e o trabalho" $\left(\mathrm{A}_{1}\right)$. Nesse sentido, considerou que a casa deveria estar localizada a 5 quadras da padaria em que Bruno trabalha e do parque em que Alice trabalha. Para tal, determinou um eixo de simetria no qual identificou 5 pontos os quais satisfazem essas novas condições propostas (Figura 6). O que o aluno fez corrobora o que Polya (2006) indica como primeira etapa na Metodologia da Resolução de Problema: o aluno tem de entender, claramente, o que é solicitado resolver, o que não aconteceu ao acrescentar novas hipóteses ao mesmo.

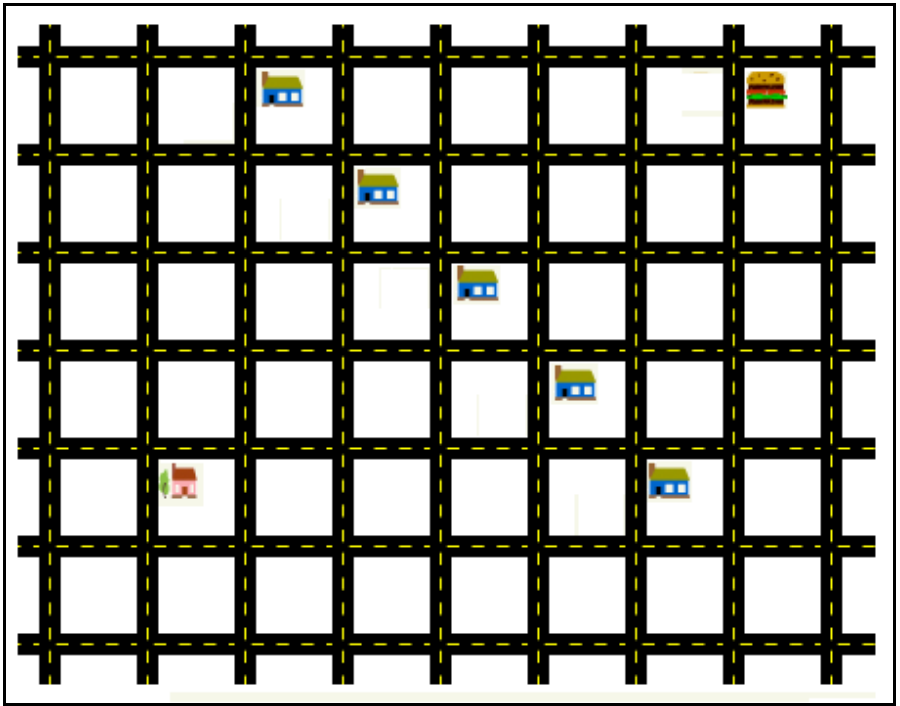

Figura 6 - Sugestões de moradia entre o emprego de Alice e Bruno. Fonte: $A_{1}$. 
A solução correta para o problema é apresentada na figura 7. Observe que a solução inicial, dada por $\mathrm{A}_{1}$, se aproxima do correto, muito embora ele tenha indicado apenas os pontos de coordenadas inteiras, o que corresponderia às esquinas da cidade ideal. A solução é dada pelo quadrilátero ACBD, exceto os pontos A e B.

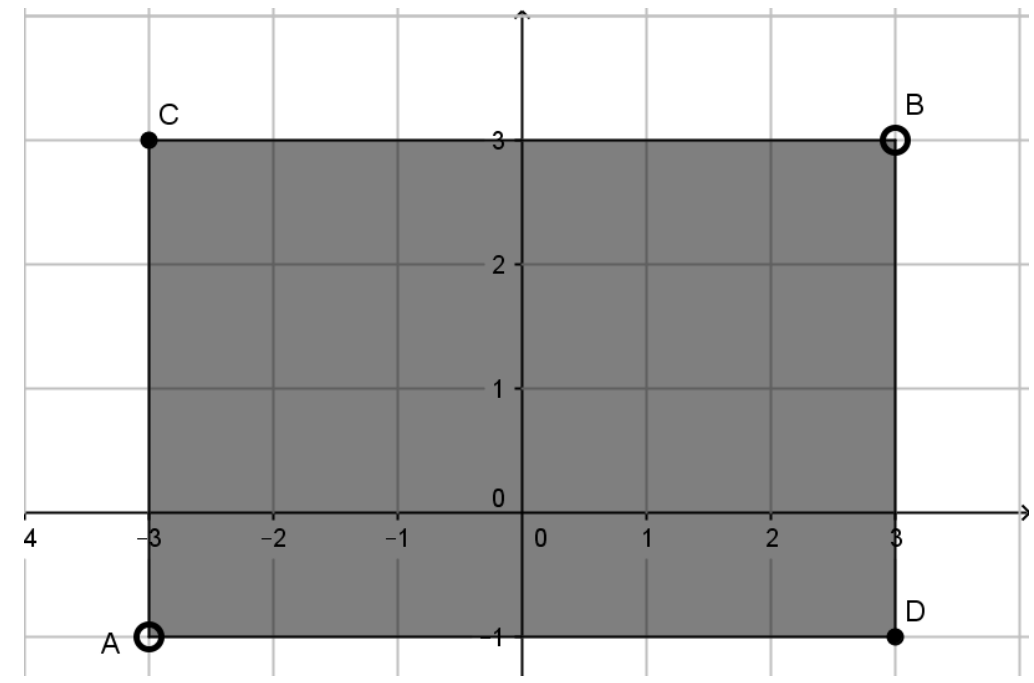

Figura 7 - Solução da situação-problema 2.

Fonte: autor.

Para a situação-problema 3, o procedimento foi o mesmo aplicado à anterior. $\mathrm{O}$ objetivo foi identificar e localizar pontos no espaço, comparando distâncias a dois pontos dados.

\section{Situação-problema 3}

Alice e Bruno estão comprando apartamento numa cidade ideal, sendo que ela trabalha no local $\mathrm{A}=(-3,-1)$ e ele, no $\mathrm{B}=(3,3)$. Como eles caminham até seus trabalhos e Bruno é um cavalheiro, ele decidiu que a soma das distâncias de seu apartamento até aos respectivos trabalhos dever ser a mínima, mas Alice não teria de caminhar mais do que ele. Localize, no mapa, onde eles devem procurar apartamento. Descreva o procedimento matemático utilizado para obter sua resposta.

$\underline{\text { Solução apresentada pela aluna } \mathrm{A}_{2}}$.

A aluna utilizou a métrica dos catetos, para obter a distância de A até B, encontrando 10 unidades. Afirmou:

como eles querem comprar um apartamento em que Alice não caminhe mais que Bruno, podemos dividir a distância do táxi pela metade e fazer uma projeção ao redor do ponto "A" em que distem 5 unidades, que representa exatamente a metade da distância do táxi, até todos os lugares possíveis, até formar o quadrado que chamamos de "circunferência do táxi". Também podemos concluir que, se o apartamento estiver nos pontos G,F,C,D ou E, os dois caminharão exatamente a mesma distância. $\left(\mathrm{A}_{2}\right)$. 
Ela expôs sua solução em papel milimetrado, como na figura 8, e parece que o feito pela aluna reafirma as palavras de Van de Walle (2009) a respeito do indicado por Hiebert sobre os estudantes não terem um método, ou memorizado soluções de um problema, uma vez que concluiu a tarefa satisfatoriamente.

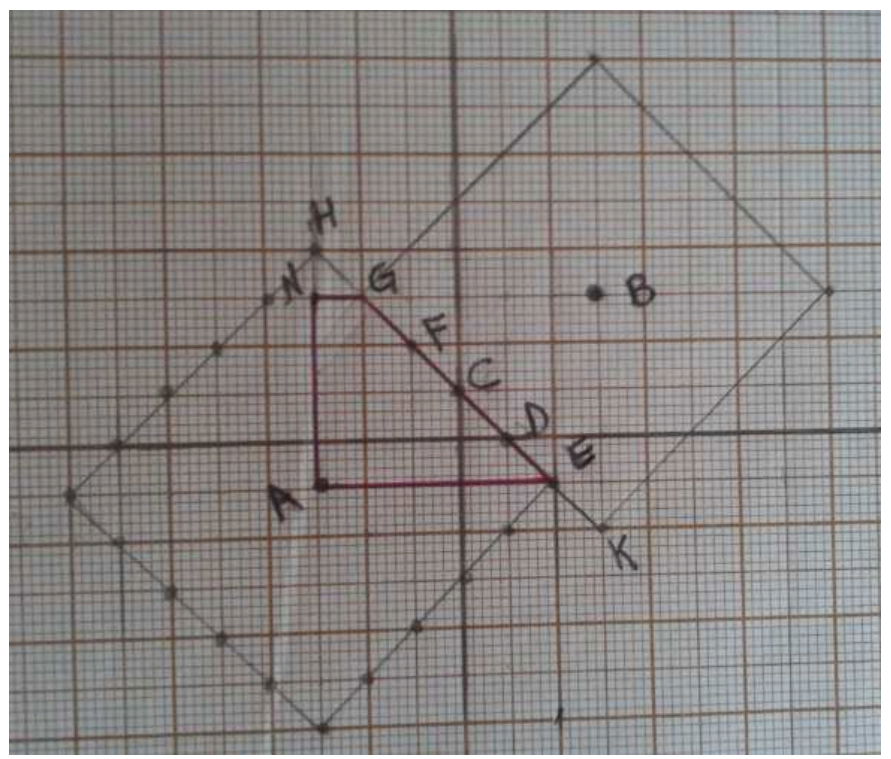

Figura 8 - Solução da situação-problema 3.

Fonte: $\mathrm{A}_{2}$.

A solução apresentada, inicialmente, se aproximou bastante da solução correta (figura 9). Por isso, entendemos que a mesma atendeu às três etapas indicadas por Polya (2006), mas não a quarta: revisitar sua resolução, caso em que teria, possivelmente, observado, por exemplo, que o ponto $(-2,0)$ seria uma localização que atenderia às exigências da situação-problema que lhe fora designada. Por outro lado, após a discussão de sua solução com o grupo, complementou-a, desta vez utilizando o recurso do GeoGebra.

A táxicircunferência de centro B e raio 5 (IKHP) fornece os lugares que distam 5u da padaria, enquanto que a LQMJ corresponde ao entorno do trabalho de Alice. A região interna ao quadrilátero $\mathrm{ACBQ}$ representa o local em que a soma das distâncias aos dois locais é igual a 10u, enquanto que a região ACPQ representa os lugares em que poderiam comprar o apartamento, de modo a Alice caminhar menos do que Bruno. $\mathrm{O}$ segmento PQ corresponde aos locais que equidistam dos dois trabalhos e foi, aproximadamente, aquele representado pelo aluno $A_{1}$, uma vez que não observou a possibilidade de mais de um ponto, além dos cantos das quadrículas. 


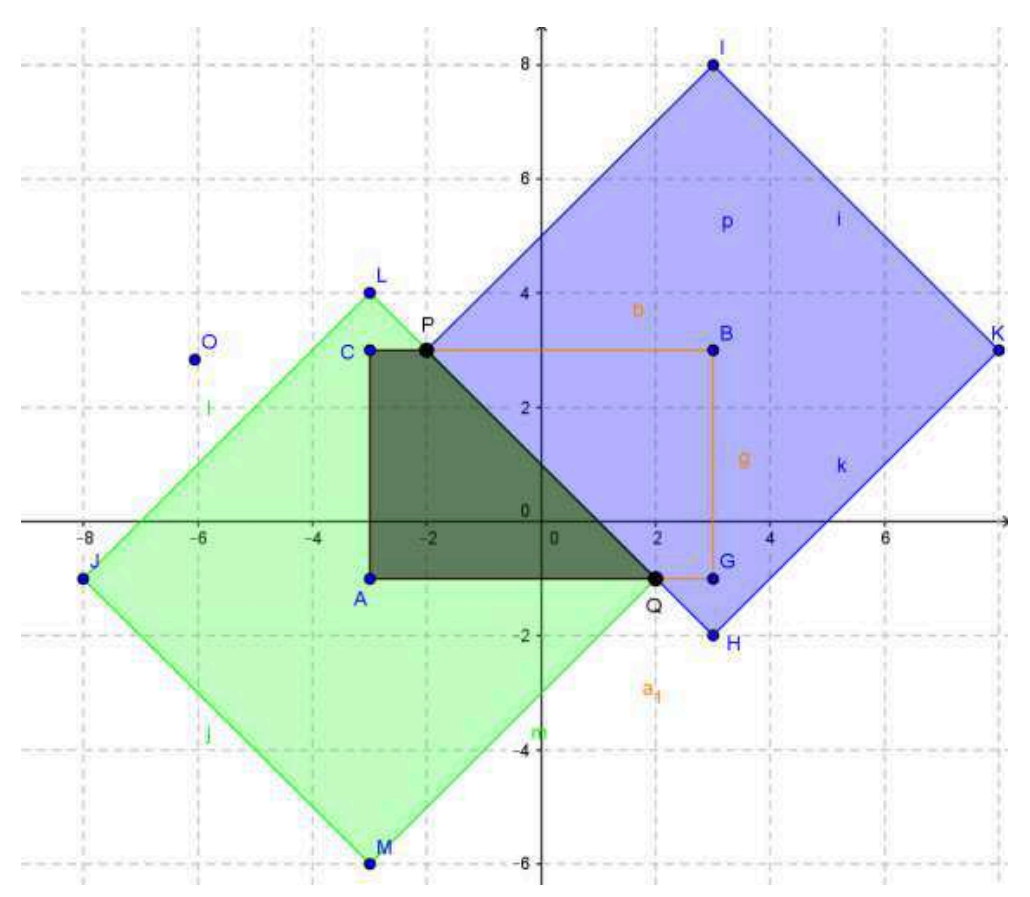

Figura 9 - Solução correta da situação-problema 3.

Fonte: autor.

Dando continuidade à situação-problema anterior, o qual preparou para a obtenção de pontos equidistantes de dois pontos dados, e a consequente diferença em termos da unicidade desses, na Geometria Euclidiana, a atividade 4 objetivou obter "os pontos médios" das distâncias. A partir da discussão em grande grupo das soluções da situação-problema 3, foram trazidas as resoluções para a sala de aula de forma mais dinâmica, com alguns retomando e fazendo no papel milimetrado e outros no GeoGebra.

\section{Situação-problema 4}

Alice e Bruno procuram um apartamento na cidade ideal para comprar, sendo que ela trabalha no local $A=(-3,-1)$, ele no $B=(3,3)$ e ambos querem fazer $\mathrm{o}$ deslocamento até o local de seus trabalhos caminhando. Eles decidem que o apartamento deve estar localizado de modo que os dois caminhem exatamente a mesma distância até seus locais de trabalho. Localize onde o casal poderia comprar um apartamento. Faça a representação no mapa e apresente os cálculos realizados para tal.

$\underline{\text { Solução apresentada pelo aluno } \mathrm{A}_{4}}$.

A aluna apresentou a solução correta feita no papel quadriculado, como apresentado na figura 10. Não justificou sua solução, apenas calculou a táxidistância entre os dois pontos, corretamente, construiu as táxicircunferências de raio iguais a 5 
unidades e, de centro, nos pontos A e B. Grifou em colorido o segmento e indicou, abaixo, "Pontos Médios das distâncias" $\left(\mathrm{A}_{3}\right)$. Ao que tudo indica, essa aluna atinge aquilo que é indicado nos $\mathrm{PCN}^{+}$, ao conseguir estratégia de resolução e relacionar diferentes conhecimentos, tendo perseverado até obter a solução.

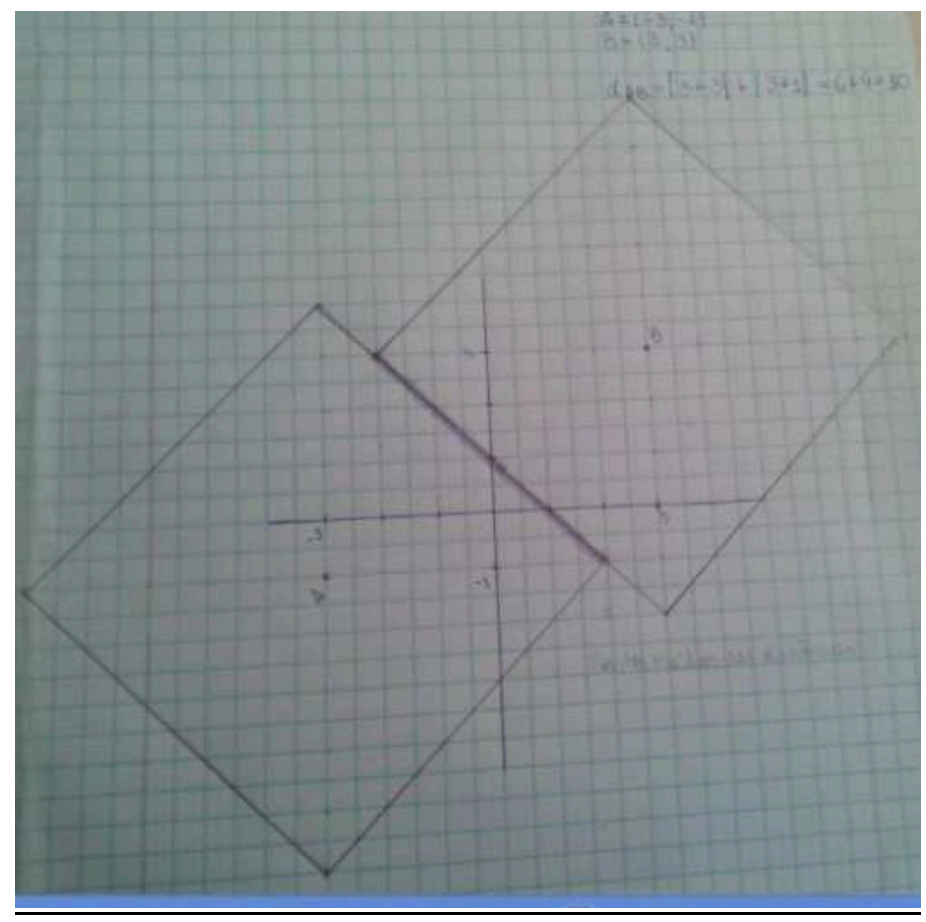

Figura 10 - Solução correta da situação-problema 4. Fonte: $A_{3}$.

Os objetivos da situação-problema 5 foram:

- promover consenso para a formalização dos conceitos de ponto médio e mediatriz;

- formalizar os conceitos de ponto médio e mediatriz;

- estabelecer semelhanças e diferenças desses conceitos nas duas geometrias.

O procedimento adotado foi a discussão, em sala de aula, coletivamente, das soluções sugeridas pelos estudantes, como indicativo do que recomendam Onuchic e Allevatto (2009) para a metodologia de resolução de problemas.

Cada aluno fez o registro em papel milimetrado ou no GeoGebra.

\section{Situação-problema 5}

Considerando a situação da cidade ideal, já abordada e discutida, e não conseguindo encontrar o local apropriado que atendesse às exigências que foram sendo acrescentadas, Alice e Bruno decidiram ampliar sua área de pesquisa. A única exigência 
que permaneceu foi de que deveriam manter a mesma distância que ambos teriam de caminhar até seus empregos. Para onde deveriam olhar?

$\underline{\text { Solução }}$

A solução discutida e obtida em consenso foi a apresentada na figura 11 . Observamos que, a partir do segmento de reta PQ, surge uma infinidade de possibilidades em que as distâncias entre os pontos A e B irão aumentando. Entretanto, a exigência de que Alice e Bruno continuem percorrendo a mesma distância aos seus empregos ocorre ao longo das semirretas PH e QI. No segmento PQ estão os pontos que dão a distância mínima. Assim, de acordo com o conceito de mediatriz: conjunto de pontos equidistantes de dois pontos dados, obtemos o lugar geométrico mediatriz na Geometria do Táxi (figura 11).

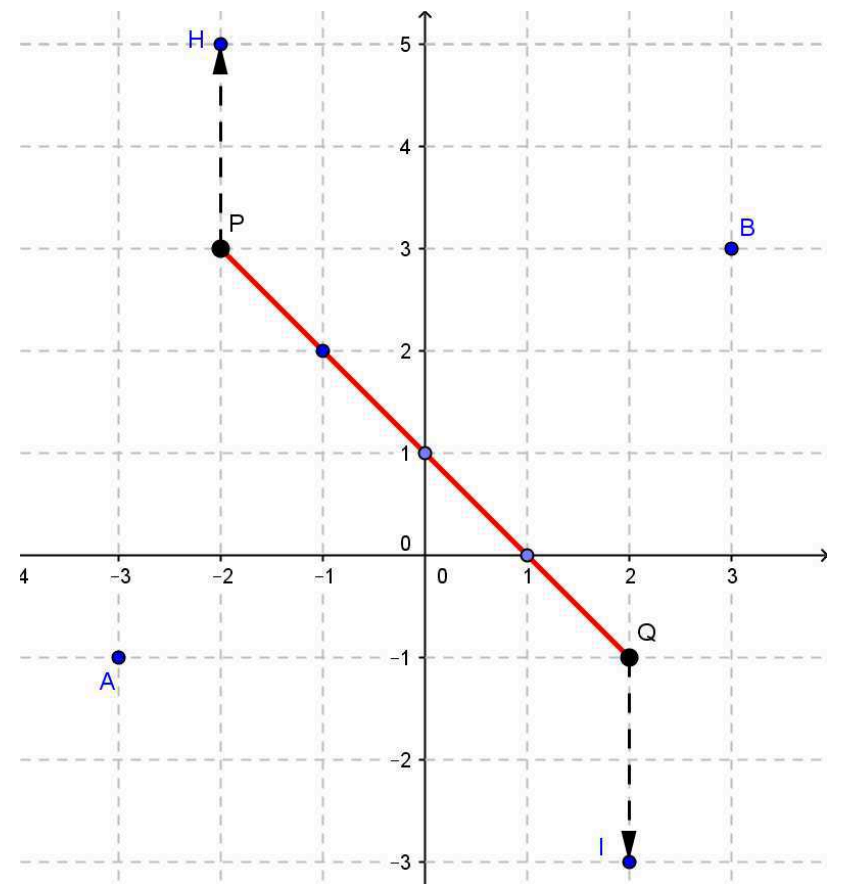

Figura 11 - Solução da situação-problema 5.

Fonte: autor.

A última situação-problema que analisamos no presente artigo teve como objetivo conceituar ponto médio e finalizar o de mediatriz a partir da aplicação dos princípios da resolução de problema na formalização. Neste ponto, os alunos reunidos no seminário previsto puderam discutir e trocar ideias, com o nosso apoio, a respeito do que haviam elaborado individualmente. 


\section{Situação-problema 6}

$\mathrm{Na}$ cidade ideal, desejamos refletir sobre alguns conceitos de Geometria. Tome os pontos $\mathrm{A}=(-3,2)$ e $\mathrm{B}=(4,-1)$. Represente-os e calcule a distância entre os dois na Geometria do Táxi. Onde se localizaria(m) o(s) ponto(s) médio(s) desse segmento nessa geometria? E a mediatriz do segmento? Estabeleça semelhanças ou diferenças entre tais conceitos nas duas geometrias.

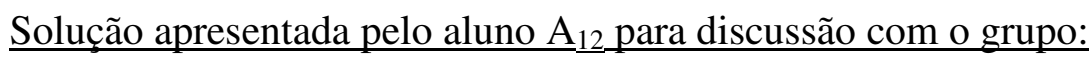

Deixamos um período de tempo à disposição para quem desejasse explicar a solução obtida, para os demais colegas poderem discutir e chegar ao consenso. Para isso, poderiam dirigir-se ao quadro e utilizar os recursos didáticos ou apontamentos que haviam registrado. $\mathrm{O}$ aluno $\mathrm{A}_{12}$ aceitou ir ao quadro apresentar o que havia feito. Disse ele:

sejam os dois pontos A e $\mathrm{B}$, com coordenadas $\left(\mathrm{x}_{1}, \mathrm{y}_{1}\right)$ e $\left(\mathrm{x}_{2}, \mathrm{y}_{2}\right)$, respectivamente. Para calcular a distância entre esses pontos, devemos utilizar as seguintes fórmulas:

- na Geometria Euclidiana, a distância é dada por

$d_{E}=\sqrt{\left(x_{2}-x_{1}\right)^{2}+\left(y_{2}-y_{1}\right)^{2}}$, enquanto que na Geometria do Táxi é dada por $\mathrm{d}_{\mathrm{T}}=\left|\mathrm{x}_{2}-\mathrm{x}_{1}\right|+\left|\mathrm{y}_{2}-\mathrm{y}_{1}\right|$.

Assim, para os pontos $\mathrm{A}=(-3,2)$ e $\mathrm{B}=(4,-1)$ temos $\mathrm{d}_{\mathrm{E}}=7,62 \mathrm{~cm}$ (figura 12 à esquerda) e $\mathrm{d}_{\mathrm{T}}=10 \mathrm{~cm}$ (figura 12 à direita).

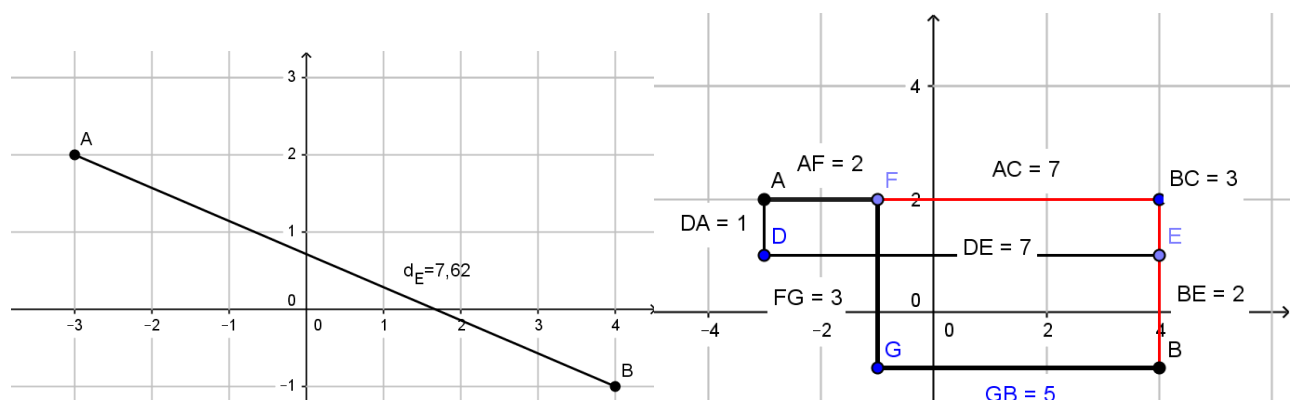

Figura 12 - Distâncias nas duas métricas.

Fonte: aluno $\mathrm{A}_{12}$.

O aluno afirma:

podemos concluir que, na Geometria Euclidiana, existe apenas um caminho entre A e B, precisamente o segmento AB (esquerda da figura 12), correspondente à respectiva distância. $\mathrm{Na}$ Geometria do Táxi existem vários outros caminhos que correspondem à $d_{\mathbf{T}}(\mathbf{A}, \mathbb{B})$ (direita da figura 12). Essa última indica algumas possibilidades. $\left(\mathrm{A}_{12}\right)$

Assim, entendemos que a resolução da situação-problema pelo aluno vai ao encontro do que é indicado no RECNEI (BRASIL, 2006), quanto à forma particular 
que cada indivíduo possui ao conceber uma solução de um problema, a partir do que percebe sobre o mesmo, assim como à realidade envolvida.

No que segue, ele conclui a respeito de ponto médio e mediatriz de um segmento na Geometria Euclidiana:

o ponto médio de um segmento $\mathrm{AB}$ é um ponto $\mathrm{C}$ desse segmento tal que $\mathrm{AC}=\mathrm{CB}$. $\mathrm{O}$ segmento $\mathrm{AB}$ tem um único ponto médio. A mediatriz de um segmento $\mathrm{AB}$ é a reta perpendicular a $\mathrm{AB}$ passando pelo seu ponto médio, além disso, é o lugar geométrico dos pontos do plano que equidistam dos pontos A e B. Isso significa que qualquer ponto escolhido da mediatriz irá estar à mesma distância das extremidades do segmento de reta que a originou. $\left(\mathrm{A}_{12}\right)$

A sua conclusão expressa o que a totalidade dos alunos deduziu ou formalizou a partir do que havia obtido, evidentemente, com alguns ajustes oriundos do debate com os demais. Ele ilustra com a construção a seguir, realizada no GeoGebra.

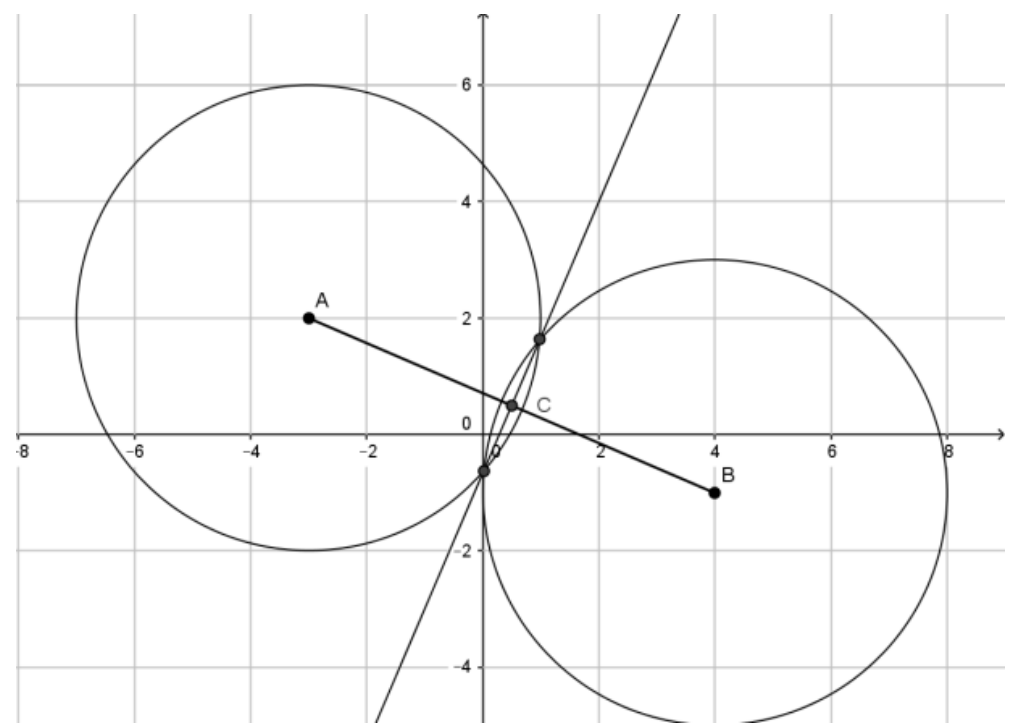

Figura 13 - Mediatriz na Geometria Euclidiana.

Fonte: aluno $\mathrm{A}_{12}$.

\section{Considerações finais}

O artigo apresentou resultados de uma investigação sobre Geometria do Táxi envolvendo resolução de situações-problema que podem ser encontradas. Ao tratar de questões reais de localização urbana, essa geometria é a que mais se aproxima da realidade, embora aborde situação ideal, mas que se encontra no cotidiano das pessoas, a saber, como realizar o deslocamento em cidades urbanizadas. Para isso, em lugar da métrica euclidiana, usamos a métrica do táxi ou dos catetos, a fim de obter ponto médio e mediatriz de um segmento, estabelecendo alguns comparativos entre os conceitos nas duas geometrias. 
As representações dos alunos, em papel milimetrado, quadriculado ou no software GeoGebra foram relevantes para a aprendizagem do conteúdo desenvolvido, o qual não era de conhecimento de nenhum dos estudantes de uma disciplina de Geometria num Mestrado Profissionalizante em Ensino de Matemática. Nesse sentido e, a partir das resoluções apresentadas e discutidas num seminário final da disciplina, destinado para tal, entendemos que o problema de pesquisa foi respondido, ou seja: como estudantes de um Mestrado Profissionalizante em ensino de Matemática, em uma disciplina de Geometria, utilizam recursos didáticos e tecnológicos para resolver problemas envolvendo Geometria do Táxi?

Consideramos que, embora nem todos os estudantes tenham resolvido plenamente cada uma das situações-problema que lhes foram designadas, após a realização do seminário, todos eles concluíram, de forma plena, as atividades. Além disso, a aprendizagem de um conteúdo novo, a partir dessas situações-problema, sem que os estudantes tivessem métodos ou regras pré-estabelecidas para a resolução, fortalecem o preconizado pelos autores e documentos citados no artigo sobre a importância da Resolução de Problemas.

Um dos principais ganhos que detectamos sobre a aplicação deste trabalho em relação ao utilizado em anos anteriores com outras turmas está no envolvimento dos estudantes na busca de soluções para as situações-problema propostas. Isso pode ser comprovado, por exemplo, na disponibilidade do aluno $\mathrm{A}_{12} \mathrm{em}$, espontaneamente, ir ao quadro apresentar sua solução e discuti-la com os colegas na presença do professor, ou seja, houve uma interatividade que contribuiu para a aprendizagem da turma.

Outro aspecto relevante foi o fato de os alunos aprenderem um pouco mais a 'pensar por si', como sugere o $\mathrm{PCN}^{+}$. A perseverança na busca e obtenção da solução completa da situação-problema 4 como, por exemplo, a ilustrada pela aluna $\left(\mathrm{A}_{3}\right)$, a qual utilizou apenas o papel milimetrado e outras realizadas no software, por grande parte dos estudantes, foi altamente produtiva para a aquisição de um conhecimento de conteúdo novo para eles, o que foi feito por meio de procedimentos matemáticos associados à intuição, analogia e estimativa originadas dos dados fornecidos na sequência de situações-problema realizada.

Mesmo que, em algumas situações, a solução não esteja completa, como no caso de $A_{2}$, o método e os recursos dos estudantes, que não sabiam o que utilizar para resolver o que fora proposto, atendem aos indicativos dados pelos pesquisadores e 
autores que tratam da Resolução de Problemas como metodologia produtiva para o ensino, relacionando representações a princípios e conceitos matemáticos, sendo esses últimos o de ponto médio e mediatriz em duas geometrias.

Os procedimentos utilizados individualmente e a interação no grupo, de forma colaborativa, foi outro ponto relevante que a pesquisa conseguiu identificar.

Portanto, acreditamos que a pesquisa aqui relatada, ao dar atenção especial ao trabalho dos estudantes na aquisição de seu conhecimento a respeito de uma Geometria que não era, até então, conhecida, reitera o afirmado por D’Ambrosio (2004), segundo o qual esse é um caminho para escapar da mesmice. Esperamos poder divulgar, em outro artigo, demais resultados obtidos nessa mesma investigação.

\section{Referências}

ALVES-MAZZOTTI, A.J.; GEWANDSZNAJDER, F. O método nas ciências naturais e sociais: pesquisa quantitativa e qualitativa. 2. ed. São Paulo: Pioneira Thomson Learning, 2002

BRASIL. Secretaria de Educação Fundamental. Parâmetros curriculares nacionais: Matemática. Brasília: MEC, 1998.

BRASIL. Ministério da Educação e do Desporto. Secretaria de Educação Fundamental. Referencial curricular nacional para a educação infantil Ministério da Educação e do Desporto, Secretaria de Educação Fundamental. Brasília: MEC/SEF, 2006. 3v.: il.

BRASIL. PCN ${ }^{+}$. Ensino Médio- Orientações Educacionais Complementares aos Parâmetros curriculares Nacionais: Ciências da Natureza, Matemática e suas Tecnologias. Brasília: MEC, 1999.

D’AMBROSIO, U. Prefácio. In: BORBA, M.de C.; ARAÚJO, J.de L. (Org.). Pesquisa qualitativa em Educação Matemática. Belo Horizonte: Autêntica, 2004. p. 11-23.

DE MAIO, W.; CHIUMMO, A. Geometrias: geometria analítica e vetorial: euclidiana e não-euclidianas. Rio de Janeiro: LTC, 2008.

DUVAL, R. Representação e conhecimento: a revolução semiótica. In: CAMPOS, T.M.M (Org.). Ver e Ensinar a Matemática de Outra Forma - entrar no modo matemático de pensar: os registros de representação semióticas). São Paulo: PROEM, 2011. p. 15-39.

EKICI, C.; KOCAYUSUFO, I.; AKÇA,Z. The Norm in Taxicab Geometry. J. of Mathematics, v. 22, p. 295-307. 1998. Disponível em: < http://dergipark.ulakbim.gov.tr/tbtkmath/article/viewFile/5000021066/5000021307>.

Último acesso em: 09 jun. 2016. 
FOSSA, J.A. Ensaios sobre a educação matemática. Belém: UEPA, 2001.

GRANGER, G.G. Filosofia do Estilo. São Paulo: Editora Perspectiva, Ed. da Universidade de São Paulo, 1974.

KALEFF, A.M.; NASCIMENTO, R.S. Atividades Introdutórias às Geometrias NãoEuclidianas: o exemplo da Geometria do Táxi. Boletim Gepem, n. 44, p. 11-42, 2004.

KRAUSE, E.F. Taxicab geometry: an adventure in Non-Euclidean Geometry. New York: Dover Publications, 1986.

LAATSCH, R. Pyramidal sections in Taxicab Geometry. Mathematics Magazine, v. 55, n. 4, p. 205-212, 1982.

LEIVAS, J.C.P. Existem bolas quadradas? Educação Matemática em Revista-RS, n. 5, p.21-25, 2003.

LEIVAS, J.C.P. Elipse, parábola e hipérbole em uma geometria que não é euclidiana. REVEMAT, v. 9, n. 2, p. 189-209, 2014.

MLODINOW, L. A janela de Euclides: a história da Geometria das linhas paralelas ao hiperespaço. São Paulo: Geração Editorial, 2010.

MOREIRA, M.A. Metodologias de pesquisa em ensino. São Paulo: Editora Livraria da Física, 2011.

ONUCHIC, L. de la R.; ALLEVATO, N.S.G. Trabalhando volume de cilindros a través da resolução de problemas. Educação Matemática em Revista-RS, v. 1, n. 10, p. 95-103, 2009.

POLYA, G. A arte de resolver problemas: um novo aspecto do método matemático. Rio de Janeiro: Editora Interciência, 2006.

SOWELL, K. O. Taxicab Geometry - a new slant. Mathematics Magazine. v. 62, n. 4, October 1989. p. 239-248.

SOUZA, H. M. de. A geometria do táxi: investigação sobre o ensino de uma geometria não euclidiana para o terceiro ano do ensino médio. $121 \mathrm{f}$. Dissertação (Mestrado Profissionalizante em Ensino Matemática). UNIFRA, 2015.

VAN DE WALLE, J. A. Matemática no Ensino Fundamental: formação de professores e aplicação em sala de aula. 6. ed. Porto Alegre: Artmed, 2009.

ZIMMERMANN, W.; CUNNINGHAM, S. Visualization in teaching and learning mathematics: a project sponsored by the Committee on Computers in Mathematics Education of The Mathematical Association of America. Washington, USA: Mathematical Association of America. 1991. 
WAGNER, D.R.; FLORES, C.R. O Discurso Geométrico Movimentando Visualidades De Professores em uma Oficina Dispositivo-Pedagógica. Vidya, 2015, v. 35, n. 2, p. 93 111,2015

JOSÉ CARLOS PINTO LEIVAS. Nascido em 1950. Ingressou no Curso de Matemática em 1970-UCPEL, tendo concluído em 1974. Participou, no último ano da graduação e, no ano seguinte, de cursos de verão na USP. Começou a lecionar na rede estadual do RS, no ano de 1972 (até 1983), logo após concluir as obrigações militares e, em 1976, na UCPEL. Em 1979, foi trabalhar na Fundação Universidade Federal do Rio Grande, atualmente FURG, onde atuou em diversos cursos, tendo chegado a professor titular. Foi coordenador da graduação e especialização. Em 1981-2 fez especialização em Análise Matemática na UFPEL e, em 1983, iniciou o mestrado em Matemática Pura e Aplicada na UFSC, concluindo em 1985. Foi convidado a aposentar-se na FURG em 2004, para atuar na ULBRA, o que o fez até 2010. De 2007-9, cursou o doutorado em Educação - Linha de Educação Matemática na UFPR, sob a orientação de Maria Tereza Carneiro, concomitantemente ao exercício profissional na ULBRA. Em 2011, passou a atuar no Programa de Pós-Graduação em Ensino de Ciências e Matemática da UNIFRA, em Santa Maria, inclusive como editor da Revista Vidya. Já foi editor da Educação Matemática em Revista-RS, diretor da SBEM-RS e secretário nacional. Tem artigos, livros e capítulos de livros publicados. Foi vice do GT4-SBEM e, desde 2015, coordenador deste GT.

Recebido: 03 de novembro de 2015

Revisado: 09 de abril de 2016

Aceito: 19 de maio de 2016 